\title{
The Relationship Between Time Management and Work Stress Among Members of Educational Planning in the General Directorates of Education in the Sultanate of Oman
}

\author{
Mundhar Hamdan Al Omairi ${ }^{1} \&$ Mohammed Talib Alkiyumi ${ }^{2}$ \\ ${ }^{1}$ Ministry of Education, Sohar; A PhD Candidate at Sultan Qaboos University, Muscat, Sultanate of Oman \\ ${ }^{2}$ Faculty of Education and Arts, Sohar University, Sohar, Sultanate of Oman \\ Correspondence: Mohammed Alkiyumi, Faculty of Education and Arts, Sohar University, P.O. Box: 44, P. Code: \\ 311, Oman. Tel: 968-9936-2383. E-mail: mkiyum@su.edu.om
}

Received: December 2, 2019 Accepted: May 31, $2020 \quad$ Online Published: July 22, 2020

doi:10.5539/ass.v16n8p1

URL: https://doi.org/10.5539/ass.v16n8p1

\begin{abstract}
The study aimed to examine the relationship between time management and work stress among the educational planning members in the General Directorate of Education in the Sultanate of Oman. It also aimed to identify whether there are statistically significant differences in time management and job stress among the participants with regard to the years of experience. The study sample consisted of 39 educational planning members. They completed the Time Management Behaviors Scale and Workplace Stressors Assessment Questionnaire. One of the main findings of this study was that the level of time management among the subjects was high, while the level of job stress was low. Results also showed a moderate and negative correlation between time management and job stress. No statistically significant difference in time management and job stress with regard to the years of experience was found. The results also supported the proposed theoretical model of the study. Based on the findings, the study recommended making use of the techniques that the participants apply to manage their time and to alleviate the workplace stressors they face. Furthermore, the education officials should pay more attention to enhancing the concept of time management by holding training courses and workshops for the ministry employees in order to increase their productivity, enhance job satisfaction, and reduce work pressures.
\end{abstract}

Keywords: Time management, Work stress, Educational planning members.

\section{Introduction}

Time is one of the most valuable resources; therefore, it must be effectively managed in various areas of life in the present and future. Time management has become an efficient basis for successful management, and an important indicator of the productivity of the organization's employees. Al-Sherida (2005, p. 9) defined time management at the administrative level as a "set of procedures used to plan, organize and control the exploitation of the official working time for the administrative officer to perform his duties."

Effective time management by organizations or institutions at the senior management and executive level is a source of achievement of the organization's objectives, raising productivity, improving the quality of work, increasing job satisfaction, increasing income and reducing work pressures. However, poor time management is one of the most important aspects of behavioral manifestations that lead to increasing work pressure on working individuals, as this is not related significantly to the lack or increase of the workload, but because of the inability of the individual to organize his time while performing his tasks (Hiyjan, 1999).

Aldhaher $(2013$, p. 156.) defined poor time management as "a state of imbalance between demands or requirements of the surrounding environment at work and an individual's ability to adapt to these requirements". With the need to improve the quality of performance, increase productivity and reduce work stress levels for employees, organizations should invest and manage their most important resource and time effectively.

In the last two decades, research and studies on the importance of time management and work stress, and the relationship between them have increased. The results of Al Rasheed (2003) showed an inverse relationship between time management and work stress. Similarly, Zaidi's (2015) results showed a negative correlation between time management and work stress. In addition, Lambert, Torres, and Tummons (2012) who investigated 
the relationship between time management of teachers and their level of work stress stated that there was no statistically significant relationship between the two variables, and their level of work pressure is low. At the Sultanate of Oman, there are rare studies that investigated the relationship between time management and working pressures in the government institutions. One of these studies was conducted by Al-Khusaibi (2012) and showed a negative correlation between time management and work pressure among faculty members at the University of Sultan Qaboos and Nizwa University.

\subsection{Statement of the Problem}

The responsibilities of educational planning members at the Directorates General of Education in the Sultanate of Oman are based on procedures documented by the quality management system of the Ministry of Education. Technically, they conduct several duties such as preparing school formations and school needs of buildings, specifiying times that cannot be exceeded during the academic year to complete these tasks and hand them to the beneficiaries on time, as well as other administrative work such as replying to official correspondence, field visits to schools, entering planning data in the educational portal, answering the inquiries of the department's auditors, answering phone calls, coordinating with the relevant departments in the joint work, attending meetings, workshops and training courses both in the Directorate and the Ministry.

They play an influential role in drawing up the educational policy in the Ministry of Education in the Sultanate of Oman. Their duties also extend to the schools such as: predicting the rates of schools absorption, enrollment of students in the existing school buildings, predicting the numbers of students and the population for the next academic year based on the development of the census of the real numbers of students for the current year. These details have to be delivered in a fixed and specified period of time annually.

Other duties include a series of tasks such as the expectation of the need for more classrooms and other educational facilities in the school buildings, the organization of student tributaries of schools, identifying the needs of new school buildings based on high student densities in some residential areas and determining the priorities of approved school buildings in the five-year plans.

These tasks and others which are extended for seven hours a day during each academic year are defined by fixed periods of readiness and delivery to beneficiaries. This results in work pressures and negative effects on the quality of performance and attitudes of members of educational planning.

\subsection{Theoretical Framework}

One of the most prominent theories that highlight the concept of time management is Stephen Covey's Time Management and Priorities Management Theory (1994/2007), which is based on the principle that any work is confined to one of the four-time management and priority matrix boxes. According to this theory, if more than $60 \%$ of the time of the individual is confined to the second box, it is considered a success in managing his time and setting his priorities. To reduce the work of the first box in the emergency crises, more work time should be spent in the second box (planning) so as to get away as far as possible from the unimportant matters represented in the third (illusion) and fourth (evasion) boxes, which is nothing but a delusion and evasion of proper time management. The researchers provided a model that represents the basic hypothesis of the current study, shown in Figure 1.

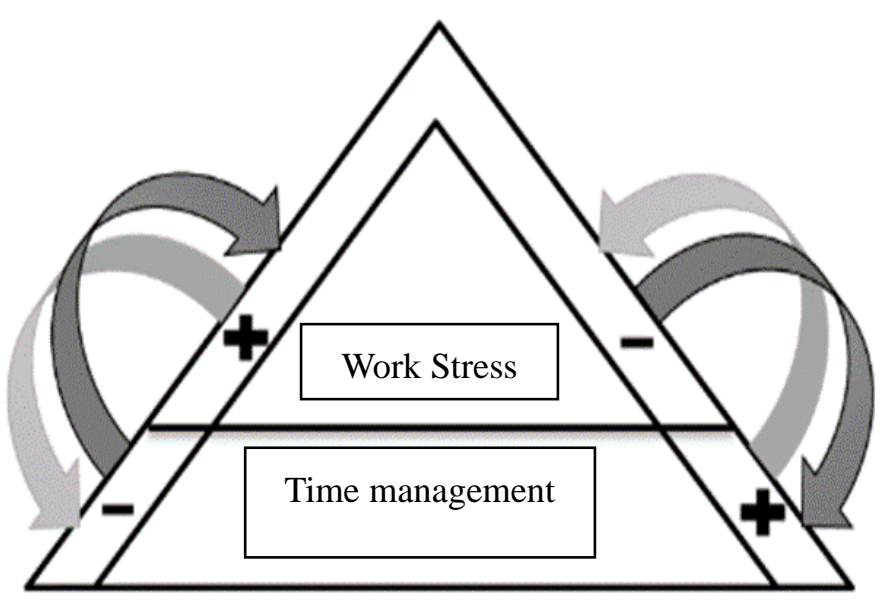

Figure 1. Study model that illustrates the negative relationship between time management and work stress 
There are many studies conducted on the concepts of time management and work pressure, and its relation with other variables. Awad's (2016) analysis of studies in this field indicated that there were 23 studies on time management variable and 43 other studies on the variable work pressure while referring to only seven previous studies conducted on the nature of the relationship between time management and work pressures. It was also revealed through the researchers' survey of the intellectual work of Oman, there is a scarcity of intellectual output in this field.

Some studies showed a negative correlation between time management and work pressures (Al-Bahouth, 2013; Al-Rasheed, 2003; Alarefi, 2008; Awad, 2016; Golabli, Rezaei, Najjar \&Namghi, 2013; Hosseini, Nourbakhsh \& Sepasi, 2013; Nunas, 2003; Zaidi, 2015). In contrast, the results of other studies indicated that there is no statistically significant relationship between the variables (Lambert et al., 2012). At the local level, the results of Al-Khusaibi (2012) indicated a statistically significant negative relationship between time management and work pressure.

These studies were applied to samples of different of institutions such as the Saudi border guards (Al-Rasheed,2003), the Secretariat of the General People's Committee for African Unity (Alna'as, 2003), a sample of managers and heads of departments of a commercial company (Alarefi, 2008), employees of a sports organization (Husseini et al., 2013), the Supply and Commodity Department staff at the National Iranian South Oil Company (Golabli et al., 2013), Saudi Ministry of Finance employees (Al-Bahouth, 2013), bank managers (Zaidi, 2015), school teachers (Lambert et al., 2012), and a sample of faculty members of the universities of Sultan Qaboos and Nizwa (Al-Khusaibi, 2012).

\subsection{Hypotheses}

The first hypothesis (H1) there is a negative correlation between the time management and the level of work stress of members of educational planning in the General Directorate of Education in the Sultanate of Oman.

The second hypothesis (H0) there are no statistically significant differences at the level of significance $(\alpha \leq 0.05)$ in the management of time and work stress of members of educational planning in the General Directorate of Education in the Sultanate of Oman due to the variable years of functional experience

\section{Method}

\subsection{Methodology of the Study}

This study is based on the methodology of quantitative correlative research because it is considered the most appropriate method in the field of study in order to obtain data on the strength and size of the relationship between the two variables (time management and work pressure) among the members of educational planning in the General Directorates of Education and its educational supervision offices in the Sultanate of Oman.

\subsection{Study Sample}

The study was applied to a non-probabilistic sample using the appropriate technique. A response of 39 members was obtained, representing approximately $90.7 \%$ of the total study population. 4 members were unable to respond due to the difficulty in reaching them.

\subsection{Tools}

The researchers used questionnaires as a tool to collect the data needed for this study. It is considered to be the most appropriate scientific research tool in which data can be collected about the study variables (time management and work pressure) to achieve the objectives of the study and test hypotheses.

\subsubsection{Time Management Questionnaire}

The Time Management Behaviors Scale (Macan, 1994) was used to measure the time management level of the target sample. The researchers translated the scale and formulated it to suit the Arabic language, after taking the prior approval of the scale designer for use in this study. The standard scale consists of fifteen items. Four items were added based on the feedback of the arbitrators in the stage of measuring the validity of the content. Therefore, the questionnaire comsisted of nineteen items in its final version. The items are answered according to the Likert scale by selecting one of the five alternatives: always, often, sometimes, rarely, and never. The internal consistency reliability was measured by the $\alpha$-Cronbach equation. The stability coefficient value was 0.68 .

\subsubsection{Work Pressure Questionnaire}

The researchers used the Workplace Stressors Assessment Questionnaire (Mahmood, Coons, Guy \& Pelletier, 2010) to measure the level of work pressure. The researchers translated the scale and formulated it to suit the 
Arabic language after taking the prior approval of the authors of the scale to be used in this study. The scale consists of 22 items. Content validity was measured. The coefficient of internal consistency stability was measured by the Alpha Cronbach equation, and the alpha coefficient was 0.82 which is a very good stability factor.

\section{Results}

\subsection{Results of the First Hypothesis}

Regarding the first hypothesis, there is a negative correlation between the time management and the level of work pressure of members of educational planning in the General Directorate of Education in the Sultanate of Oman. The Pearson Correlation coefficient was calculated between the two variables and the results are shown in Table 1.

Table 1. The relationship between time management and work pressure

\begin{tabular}{ccc}
\hline Relationship & Sample size N & Pearson correlation coefficient value \\
\hline $\begin{array}{c}\text { The relationship between time management } \\
\text { and work pressure }\end{array}$ & 39 & $-0.35-*$ \\
\hline
\end{tabular}

The data shows that the Pearson correlation coefficient between time management and working pressure is $r=$ -0.35 indicating that the relationship between time management and work pressure of the sample is a negative and average correlation (Gay, Mills, \& Airasian, 2006).

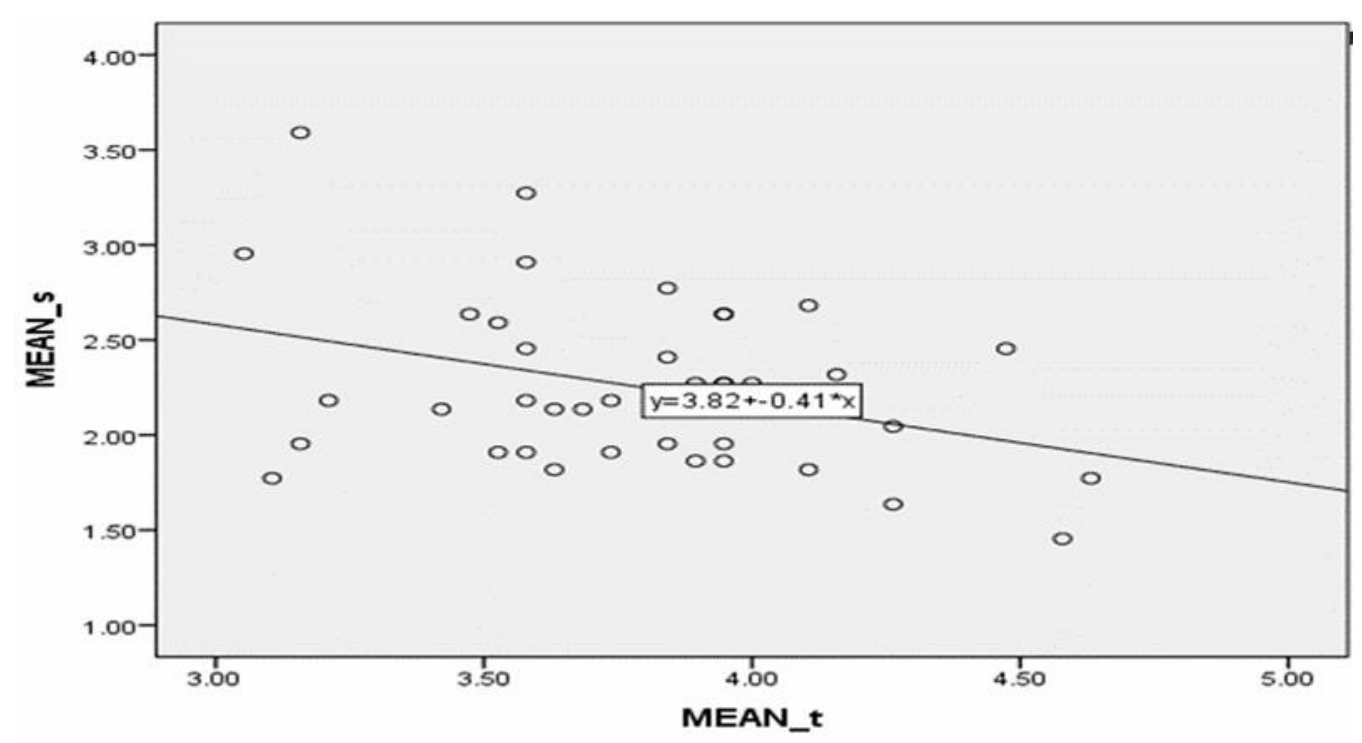

Figure 2. The inverse correlation graph between time management and work pressure in the study sample

In the same context, Figure 2 shows the distribution of moderately inverse or semi-linear relationship between the two variables. In calculating the common variance between the variables, it equals of $12 \%$ of the data or responses of the individuals involved in the study representing the regularity of the relationship between the two variables, while the remaining $88 \%$ represents the dispersion of the relationship between the two variables.

\subsection{Results of the Second Hypothesis}

There are no statistically significant differences at the level of significance $\alpha \leq 0.05$ in the management of time and work pressure of members of educational planning in the General Directorate of Education in the Sultanate of Oman due to the variable years of functional experience: from one year to less than ten years $(1-<10)$, from ten years to under fifteen $(10-<15)$, and fifteen years and above $(15-\infty)$. The researchers used the one-way analysis of MANOVA, and the results of the analysis of the differences are as follows: 
Table 2. Wilkes Lambda value in one-way MANOVA multivariate analysis

\begin{tabular}{ccccccc}
\hline $\begin{array}{c}\text { Independent } \\
\text { variable }\end{array}$ & $\begin{array}{c}\text { The value of } \\
\text { Wilkes Lampada }\end{array}$ & $\begin{array}{c}\text { Values } \\
\mathrm{F}\end{array}$ & $\begin{array}{c}\text { The degree of } \\
\text { freedom } \\
(\mathrm{df})\end{array}$ & $\begin{array}{c}\text { degree } \\
\text { freedom } \\
\text { (Error df) }\end{array}$ & $\begin{array}{c}\text { Level of } \\
\text { significance } \\
\mathrm{P}\end{array}$ & $\begin{array}{c}\text { Size of the effect } \\
\text { (ETA Box) Partial } \\
\text { Eta Squared }\end{array}$ \\
\hline $\begin{array}{c}\text { Years of functional } \\
\text { experience }\end{array}$ & 0.389 & 1.606 & 4 & 70 & 0.182 & 0.084 \\
\hline
\end{tabular}

Table 3. Results of MANOVA One-Way Multivariate Analysis

\begin{tabular}{cccccc}
\hline Independent variable & Dependent variables & $\begin{array}{c}\text { Values } \\
\mathrm{F}\end{array}$ & $\begin{array}{c}\text { The degree } \\
\text { of freedom } \\
\mathrm{df}\end{array}$ & $\begin{array}{c}\text { Level of } \\
\text { significance } \\
\mathrm{P}\end{array}$ & $\begin{array}{c}\text { Impact Size (ETA Box) } \\
\text { Partial Eta Squared }\end{array}$ \\
\hline $\begin{array}{c}\text { Year Groups } \\
\text { Functional years of experience }\end{array}$ & Time management & 2.089 & 2 & 0.139 & 0.104 \\
\hline
\end{tabular}

Table 2 shows the statistical values: $\Lambda=0.839, \mathrm{~F}(4,70)=1.606, \mathrm{P}=0.182$, partial $\eta 2=0.084$. The value of the Wilkes Lambda test is $\Lambda=0.839$ and the corresponding $\mathrm{F}$ value is 1.606 . The value of $\mathrm{P}=0.182$ is greater than the significance level of 0.05 . Therefore, the results support the second hypothesis (H0). In other words, there are no statistically significant differences at the level $\alpha \leq 0.05$ in the management of time and work pressure of members of educational planning in the General Directorate of Education in the Sultanate of Oman due to the variable years of functional experience. The effect according to ETA box $\eta 2=0.084$ indicates a weak practical indication of the strength of the relationship between the independent variable (functional years of experience) with two dependent variables: time management and work pressure (Leech, Barrett \& Morgan, 2005).

This is confirmed by the results of Table 3. The results show that the value of $\mathrm{F}=2.089$ and the degree of freedom is $d f=2$ and the value $P=0.139(\alpha \leq 0.05)$ for the level of time management among members of educational planning in the General Directorates of Education in the Sultanate of Oman due to the variable: years of functional experience (from one year to less than 10 years, 10 years to less than 15 years, 15 years and above). ETA $(\eta 2=0.104)$ indicates a weak practical indication of the strength of the relationship between the independent variable (years of functional experience) and the first dependent variable: time management (Leech, Barrett \& Morgan, 2005).

Test of the multiple variance analysis between the second dependent variable (work pressure) and the independent variable (years of functional experience) reveals that the value of $F=0.281$; the degree of freedom is $d f=2$. In addition, the value $P=0.756$ is greater than the significance level $(\alpha \leq 0.05)$ for the level of work pressure among the members of the educational planning in the General Directorates of Education in the Sultanate of Oman due to the variable years of functional experience (from one year to less than 10 years, 10 yearsto less than 15 years, 15 years and above), while the values of Impact size according to square ETA to $\eta 2=$ 0.15 denote a weak strength of the relationship between the independent variable (functional years' experience) with the second dependent variable (work pressure) (Leech, Barrett \& Morgan, 2005).

Figures 2 and 3 show that the differences between the three groups in years of functional experience among the members of educational planning have no statistically significant effect on their time management. This is confirmed by the two figures above. The difference between the lowest mean of $3.58 \mathrm{M}$ for the second row of group 1 (10 years to under 15 years) and the highest mean of $3.87 \mathrm{M}$ for the third row of group 1 (15 years and over) is small and 0.29 compared to the minimum between 3.05 . The maximum value is $=4.63$ in the time management variable, which indicates the existence of quasi-homogeneity among members of the three groups responses to variable time management.

\section{Discussion}

\subsection{Discussion of the First Hypothesis Result}

The results of the first hypothesis showed that there is a negative correlation between time management and level of work pressure. It means that the better the time management of the members of educational planning, the lower the level of work pressure is, and vice versa. This result is consistent with most of the previous studies (Alarefi ,2008; Al-Bahouth , 2013; Al-Khusaibi 2012; Alna'as; 2003, Al-Rasheed, 2003; Gerald, 2006; Haidari, 2006; Husseini et al., 2013; Zaidi, 2015). 
In addition, the results of the study are consistent with the theory of time management matrix of Stephen Covey (1994/2007). This is because the pre-planning and the increase of work quality in the planning box will lead to improved productivity and less stress as mentioned in the theory. It includes activities such as prioritization and scheduling, time management, self-awareness and avoidance of time waste carried out by the individual in the work environment and beyond. All these practices and methods serve as the cornerstone for optimal time management. This, in turn, reduces the space of the rest of the time management matrix boxes (emergency, illusion, and evasion), resulting tension, and work stress among individuals in their lives in general and business environments. The results of this study are also consistent with the model of the study assumed by the researchers and derived from the theory of Covey (1994/2007), where the model shows that the relationship between time management and work pressure is an inverse or negative relationship. That is, the level of time management has increased by prioritizing, organizing time and anticipating the work of educational planning members, thereby reducing the levels and sources of their work pressures and vice versa, as illustrated in Figure 3.

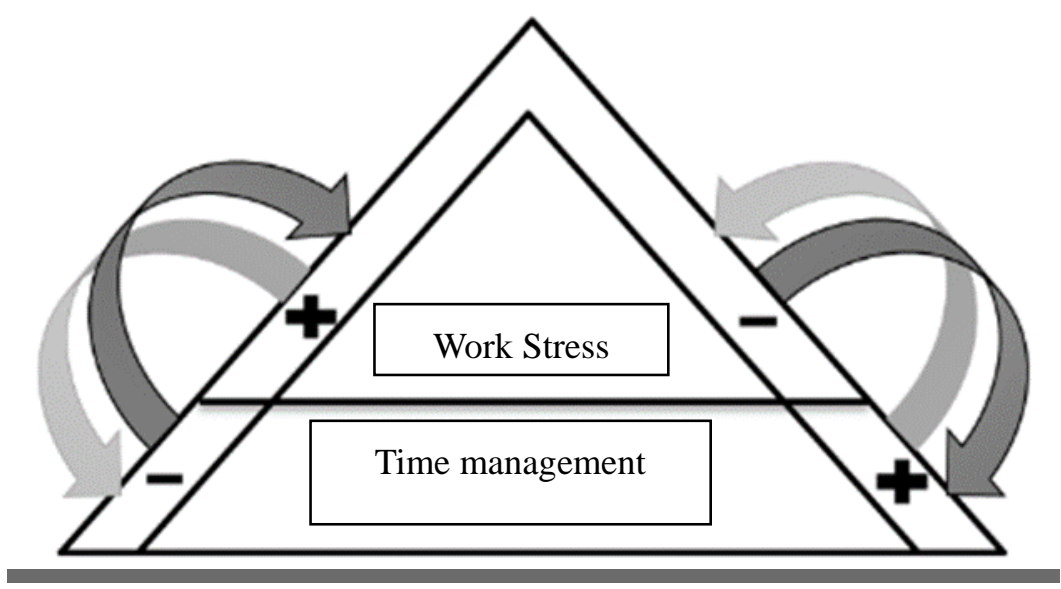

Figure 3. illustrates the negative relationship between time management and work pressure

In the same context, the results showed that the members of the educational planning participating in the study manage their working hours at a high level and that the level of their work pressure is low. The reason is that the nature of their job requires them to apply advanced planning methods to accomplish the assigned work. For example, to carry out the task of preparing the school formations, the member of the educational planning uses the census of the realistic numbers of students for this academic year. Another example is predicting the exact scientific standards of the expected numbers of students in the next academic year, as in the case with the preparation of school building configurations. This indicates that the specificity of the tasks of the educational planning member is necessitated by the daily practice of planning and prioritizing tasks, which is the basic skill of time management.

The reason behind these results could be due to the fact that most of the educational planning members are mathematics teachers. Essential procedures and computational skills are required to plan the educational needs efficiently such as the ability to accurately predict the number of students, growth rates, building additions, and budget vacancies. Another reason may be attributed to the adequacy of the number of educational planning members in the governorates and their supervisory offices. Some governorates have high student densities compared with others, and there are many states and districts with more than 100 schools, such as Muscat. The planning work is divided internally and informally among the members of the educational planning as each member is assigned to specific tasks and work related to the schools in a specific city or/and region.

A third reason may also be attributed to the keenness of the members of the educational planning to be regular and not to waste the official working time, especially in the presence of effective administrative control. All of these practices, skills, and characteristics characterized by the member of the educational planning ensure that the time is managed in an orderly manner which directly and automatically reduces the sources and causes of the work pressures he/she faces. This is proven by the results of the study through the reverse relationship and the average size between time management and work pressure. It is also understood that most members of educational planning work within the second box (planning and quality box) according to the Covey time management theory (1994/2007), thus reducing the area of the first box (emergency), the third box (illusion) and 
the fourth Box (evasion).

\subsection{Discussion of the Second Hypothesis}

The results of the study also support the second hypothesis (H0). That is there are no statistically significant differences at the level of significance $(\alpha \leq 0.05)$ ) between time management and work pressure among members of educational planning in the General Directorates of Education in the Sultanate of Oman due to the variable years of functional experience: 1 year to less than 10 years, 10 years to under 15 years and 15 years and above.

This finding is in line with Haidari's (2006) study, which found that there were no statistically significant differences in time management and working pressures among primary school principals in the Kingdom of Bahrain due to the variable years of functional experience. The results of this study are also consistent with the Alkharief (2011) which reveals that there are no statistically significant differences in the time management and working pressures of the officers working in the General Directorate of Civil Defense in Riyadh, Saudi Arabia due to the variable years of functional experience. In addition, Al-Khusaibi (2012) states that there are no statistically significant differences in time management and working pressure among faculty members at Sultan Qaboos and Nizwa Universities in Sultanate of Oman due to the variable years of functional experience. Smilarly, Al-Bahouth's (2013) study shows there are no statistically significant differences in the time management and working pressures of the employees of the Ministry of Finance for budgetary and organizational affairs in Riyadh, Saudi Arabia.

On the other hand, the results of this paper are inconsistent with Salem's (2011) who found significant differences in time management and work stress among UNRWA school principals in Gaza City in the occupied Palestinian state due to the variable years of functional experience for those with long career experience. Lambert et al. (2012) also found significant differences in time management and work stress among high school teachers in Missouri, due to the variable years of experience in favor of those with recent years of work experience. Alzibin (2012) states that there are significant differences in the management of time and work pressures of the holders of administrative positions in the public institutions in the Hashemite Kingdom of Jordan due to the variable years of functional experience for those with long career experience.

The researchers explain that the disparity between the members of educational planning in the General Directorate of Education in the number of years of work experience are statistically dependent on their time management and on the level of their work pressures. Therefore, there is a similarity between the three functional experience groups (one year to less than 10 years, 10 years to less than 15 years, 15 years and above) in terms of time management and work pressure. The members of the educational planning with long career experience manage their time at work almost as much as the members of educational planning with recent experience.

This may be due to the existence of the positive work pressure that motivates educational planning members to efficiently manage and organize their working hours. Furthermore, there is a unified system developed for the performance of work and job functions among all members of educational planning in the education departments based on documented procedures by the Quality Management System in the Ministry's General Office. Through this system, the tasks entrusted to the members of the educational planning are determined by specific time periods for completion and delivery to the beneficiaries in the field of education. Therefore, a common vision among the educational planning members provides similar methods and practices among most members of educational planning with various functional experiences, such as setting short and long term priorities and objectives, planning and forecasting the required work ahead of schedule, setting deadlines for tasks, and using modern technologies to accelerate the pace of business completion while maintaining the quality of the work done, as well as the distributing work equally among them. All these methods and practices ensured that the members of educational planning run their work time well regardless of the number of years of functional experience.

In addition, members of educational planning with long career experience face the same pressures as the educational planning members with less functional experience. This may be because most educational planning members have similar skills and methods in dealing with the same levels of work stress they face regardless of the number of years of work experience they have had. For example, they haveprofessional and technical ability to do business in a team spirit away from work disputes. Other reason may include the clarity of roles and responsibilities, adequate powers to carry out their work, the support and respect they receive for their efforts by their superiors, and the non-conflict and accumulation of work. All of these reasons in light of low levels of negative work stress.

In the same context, this study proved that the number of years of functional experience spent by the educational 
planning member during his career is not a constant criterion for judging his experience in doing business properly; but his ability to exploit and manage work time and relieve pressure. In other words, the productivity and level of work time management of the member with less work experience is higher than that of another educational planning officer previously appointed in the post due to several skills and other factors enjoyed by the member with a modern functional experience. These skills include his ability to participate in the collective work, the use of modern technologies in the achievement and exploitation of time, innovating new methods of management and investment of time, self-awareness and avoidance of time waste, organization of the office and place of work, the ability to allocate specific times to accomplish each task, and finally the fragmentation of functional complex tasks into smaller tasks that can be controlled. This is reflected in this study by the existence of a negative correlation relationship and medium strength between time management and the work pressure of members of educational planning in the General Directorate of Education in the Sultanate of Oman.

Based on the above, it can be seen that time management, as Scholler (1979/1980) sees it, is considered to be a comprehensive and integrated concept that is not limited to administrative work, and is not limited to a specific place or period of time rather than the other through which the employees can accomplish the tasks and objectives that enable it to work effectively. Ross (1986) points out that there is no perfect time management for every individual, time or place. Rather, it is important to acquire the necessary skills that help to invest time and reduce time waste, even if it requires sacrificing some of the prevailing customs and tradition in dealing with subordinates in a way that helps develop the working environment to make them more responsive to the requirements of the performance of business at the times specified or available to them.

\section{References}

Alarefi, S. (2008). The relationship between time management and job stress [Master thesis, King Saood University]. Retrieved from http://faculty.ksu.edu.sa

Al-Bahouth, A..(2013). Time management skills and its relationship to with job pressures in perspective of the staff of the Ministry of Finance for budgetary and organizational affairs in Riyadh [Master thesis, Naif Arab University for Security Sciences]. Retrieved from http://repository.nauss.edu.sa

Aldhaher, N. (2013). Effective time leadership. Alalam Akotob.

Alkharief, S. (2011). The relationship between management and working pressures of the officers working in the General Directorate of Civil Defense in Riyadh. Journal of scientific research, 3(2), pp.125-135. Retrieved from http://search.mandumah.com/Record/534747

Al-Khusaibi, A. (2012). Time management and job stress among technical faculties of Sultan Qaboos University and Nizwa University [Unpublished master thesis]. Nizwa University.

Alna'as, E. (2003). Impact of time management on job stress in general management [Master's thesis, Institute of Planning Postgraduate]. Retrieved from http://kenanaonline.com/files/0008/8734/BOOK2.pdf

Al-Rasheed. J. (2003). Time management and its relationship with job stress among Establishments managers and head departments [Master's thesis, Naif University of Security Sciences]. Retrieved from http://repository.nauss.edu.sa

Al-Sherida, J. (2005). Factors Affecting the effectiveness of time management of administrators working at private universities in Jordan (Publication No. 587202) [Master thesis, Amman University).Dar AlMandumah.

Alzibin, R. (2012). The impact of time management on job stress among the employees of administrative jobs in the Directorates of Jordan Ministry of Interior (Publication No. 563173) [Master thesis, Om Darman Islamic University). Dar AlMandumah.

Awad. A. (2016). Effect of time management strategy on facing systematic job stress of academic work. Journal of Social Services, 55, 115-187.

Covey, S. (2007). Priority management: Most important first (Translated by Alsaid Mitwali Hassan). Alriyadh: Jarir Bookshop (the original work was published in 1994).

Gay, L., Mills, G., \& Airasian, P. (2006). Educational research competencies for analysis and application (8th ed.). Prentice Hall.

Golabli, M., Rezaei, S., Najjar, L., \& Nameghi, M. (2013). The survey of the relationship between time management with job stress and performance in material and procurement management of N.I.S.O.C (National Iranian South Oil Company). Journal of Basic and Applied Scientific Research, 3(10), 33-39. 
Retrieved from https://www.semanticscholar.org/paper/The-Survey-of-Relationship-between-Time-Manage ment-Golabli-Rezaei/b35f8bfb6184a184a80cd16dfdcef30fcf097faa

Haidari, B. (2006). Methods of time management among the governmental primary school principals in Kingdome of Bahrain and its relationship with job stress of the school administrative work. Journal of Science and Psychology, 7(2), 266-267.

Hiyjan, A. (1999). Job stress: Comprehensive approach for studying resources, results, and management. General Management Institution.

Hosseini, S., Nourbakhsh, P., \& Sepasi, H. (2013). Relationships between time management and job stress. Archives of Applied Science Research, 5(1), 301-307. Retrieved from https://www.scholarsresearchlibrary. com/articles/relationships-between-time-management-and-job-stress.pdf

Lambert, M., Torres, R., \& Tummons, J. (2012). The influence of time management practices on job stress levels among beginning secondary agriculture teachers. Journal of Agricultural Education, 53(1), 45-56. https://doi.org/10.5032/jae.2012.01045

Leech, L., Barrett, C., \& Morgan, A. (2005). SPSS for intermediate statistics: Use and interpretation (2nd ed.). Lawrence Erlbaum Associations Publishers.

Macan, T. (1994). Time management: Test of a process model. Journal of Applied Psychology, 79(3), 381-391. https://doi.org/10.1037/0021-9010.79.3.381

Mahmood, M., Coons, S., Guy, M., \& Pelletier, K. (2010). Development and testing of the workplace stressors assessment questionnaire. JOEM, 52(11), 1-10. https://doi.org/10.1097/JOM.0b013e3181fb53dc

Ross, J. (1986). Managing productivity. Johne Willey-Hill Dook.

Scholler, R. (1980). Tension management means time management (translated by Salah Abdulkareem Alsafadhi). Amman: Arabic Journal of Management (Original work was published in 1979).

Zaidi, U. (2015). Time management and professional stress among bank managers: A correlational study. IOSR Journal of Business and Management, 17(1), 83-87. https://doi.org/10.9790/487X-17128387

\section{Copyrights}

Copyright for this article is retained by the author(s), with first publication rights granted to the journal.

This is an open-access article distributed under the terms and conditions of the Creative Commons Attribution license (http://creativecommons.org/licenses/by/4.0/). 